\title{
Correlation among Lens Opacities Classification System III grading, the 25-item National Eye Institute Visual Functioning Questionnaire, and Visual Function Index-14 for age-related cataract assessment
}

\author{
Yu Wan · Yinhao Wang • Liming Zhao $\cdot$ Min Sun $\cdot$ Li An · Yang Yang • \\ Aimin Jiang $\cdot$ Yanhui Xu $\cdot$ Zhimin Chen $\cdot$ Xuemin Li
}

Received: 16 September 2019/Accepted: 24 March 2020/Published online: 5 April 2020

(C) The Author(s) 2020

\begin{abstract}
Purpose To evaluate the relationship between cataract types and subjective visual function among patients with age-related cataract.

Methods This was a prospective, multicenter, 831 Chinese patient-based, cross-sectional study. Patients were administered the Visual Function Index-14 (VF14) and the 25-item National Eye Institute Visual Functioning Questionnaire (NEI-VFQ-25) to evaluate their subjective visual function. Lens Opacities Classification System III (LOCS III) was used to evaluate the type of cataract. Relationships among these parameters were analyzed.
\end{abstract}

Yu Wan, Yinhao Wang, Liming Zhao, Min Sun, Li An, Yang Yang, Aimin Jiang, Yanhui Xu and Zhimin Chen have contributed equally to this work.

Electronic supplementary material The online version of this article (https://doi.org/10.1007/s10792-020-01353-0) contains supplementary material, which is available to authorized users.

Y. Wan $\cdot$ Y. Wang $\cdot$ X. Li $(\bowtie)$

Peking University Third Hospital, Beijing, China

e-mail: 1xmlxm66@sina.com

L. Zhao

Beijing Fengtai Hospital, Beijing, China

M. Sun

Huabei Petroleum General Hospital, Renqiu, China
Results LOCS III cortical (C) and posterior subcapsular scores are negatively associated with VF-14 $(r=-0.188, P<0.01 ; r=-0.146, P<0.01)$ and total score of NEI-VFQ-25 $(r=-0.223, P<0.01$; $r=-0.160, \quad P<0.01)$, respectively; LOCS III nuclear opalescence (NO) score is positively associated with VF-14 $(r=0.087, P<0.05)$ and total score of NEI-VFQ-25 $(r=0.097, P<0.05)$. In multiple linear regression, a decrease in the LOCS III C score is a significant predictor for improvement of the total score of NEI-VFQ-25 $(\beta=-1.286, P<0.05)$. In contrast, an increase in LOCS III NO score is a significant predictor for improvement of VF-14 $(\beta=3.826, P<0.01)$ and total score of NEI-VFQ$25(\beta=4.618, P<0.01)$. Patients with LOCS III C score $\leq 2$ have higher VF-14 (49.38 versus 43.74, $P<0.01)$, total $(80.73$ versus $71.58, P<0.01$ ) and subscale scores of NEI-VFQ-25 than patients with LOCS III C score $>2$.

Conclusion Cortical cataract has adverse effects on subjective visual function, while mild-to-moderate nuclear cataract has positive effects. Furthermore,

L. An

Datong Aier Eye Hospital, Datong, China

Y. Yang $\cdot$ A. Jiang

The Hospital of Shunyi District Beijing, Beijing, China

Y. Xu $\cdot$ Z. Chen

Hebei Eye Hospital, Xingtai, China 
"LOCS III C score $>2$ " can be a potential cutoff as a reference for cataract surgery without self-assessing questionnaires.

Keywords Age-related cataract - Cataract types . Subjective visual function · VF-14 · NEI-VFQ-25

\section{Introduction}

Cataract is the primary cause of blindness, which can significantly influence people's quality of life. Agerelated cataract is the most common type of cataract that injuries the visual function and quality of life for the elderly $[1,2]$. Cataract surgery can significantly improve vision, visual functioning, and the quality of life of patients [3-7]. Therefore, it is essential to determine the surgical timing for cataract. In order to comprehensively assess the status of patients with cataract, objective and subjective measures were performed and studied [6, 8-10].

The Lens Opacities Classification System III (LOCS III) is one of the most common subjective tools to grade the opacities of the lens at the slit lamp $[11,12]$. The Visual Function Index-14 (VF-14) and the 25-item National Eye Institute Visual Functioning Questionnaire (NEI-VFQ-25) are patient-perspective questionnaires that are proven to be reliable and valid [13-19]. These two questionnaires are used as a supplement for existing measurements of cataract $[9,10,20,21]$, such as visual acuity and contrast sensitivity. Several pieces of research studied the relationship between the LOCS III score and the score of vision-specific self-assessing questionnaires $[9,10]$. However, this relationship was inconsistent $[9,10]$.

In the present study, we aim to analyze the relationships among visual acuity, LOCS III scores, VF-14, and NEI-VFQ-25 scores in the Chinese population. We hope to find a potential cutoff of LOCS III scores as a reference for cataract surgery.

\section{Subjects and methods}

Subjects

This study is prospective, multicenter, Chinese population-based, and cross-sectional. A total of 831 eyes among 831 patients with bilateral age-related cataract from five different centers were enrolled between March and June 2019 in our study. Patients with glaucoma, fundus diseases, amblyopia, history of ocular surgery, and cognitive disorder were excluded in our study. This research was approved by Peking University Third Hospital Medical Science Research Ethics Committee, which was adhered to the tenets of the Declaration of Helsinki. Informed consent was obtained from all the participants.

\section{Clinical characteristics}

Uncorrected distance visual acuity (UDVA) of the operative eye (op-eye) and the non-op eye was recorded. The operative eye is defined as the eye with worse vision or more significant influence on life planned to received cataract surgery. UDVA of the opeye was categorized into four categories: normal vision $(<0.3$ LogMAR), mild vision impairment $(0.3$ to $<0.5$ LogMAR), moderate vision impairment $(0.5$ to $<1.0$ LogMAR), and severe vision impairment and blindness ( $\geq 1.0$ LogMAR). UDVA of the other eye was recorded as well. The opacity of each op-eye was assessed using LOCS III, including nuclear opalescence (NO), cortical (C), and posterior subcapsular (P) scores. A well-trained ophthalmologist graded every eye under slit-lamp examination according to standard color figures of LOCS III grading [22]. We classified the LOCS III C score into two groups, "Group C1" $(\leq 2)$ and "Group C2" $(>2)$ in our study.

\section{Self-assessment questionnaires}

Two widely used self-assessing questionnaires (VF-14 and NEI-VFQ-25) [19, 23], translated in Chinese, were completed by each subject before surgery to evaluate subjective visual function. The subscales of NEI-VFQ-25 included General Health, General Vision, Ocular Pain, Near Activities, Distance Activities, Social Functioning, Mental Health, Role Difficulties, Dependency, Driving, Color Vision, and Peripheral Vision. A well-trained ophthalmologist would explain the questions on the questionnaires to subjects who cannot figure out or understand the questionnaire by himself/herself. The subscale scores and total scores were calculated according to the scoring algorithm. Systemic diseases influencing the 
vision, including hypertension and diabetes, were recorded.

\section{Statistical analysis}

IBM SPSS Statistics for Windows (version 20.0. Armonk, NY: IBM Corp) and GraphPad Prism 5 for Windows (version 5.01. GraphPad Software, Inc) were used to analyze the data and draw graphs. Categorical variables were shown as percentage, rank variables, and continuous variables were shown as mean \pm SD or median. One sample KolmogorovSmirnov test was used to check the normality of each variable. None of the variables were normally distributed. Mann-Whitney $U$ test was used to compare the difference between two independent samples. Association among different variables was explored by the Spearman coefficient test. The coefficient $r<0.4$ indicates a weak correlation; $\geq 0.4-0.7$ indicates a moderate correlation; $\geq 0.7$ indicates a strong correlation. Multiple linear regression analysis was used to adjust confounding factors. Baseline variables that were considered clinically relevant or that showed a univariate relationship with outcome entered the multiple linear regression model. Finally, nine confounding factors were analyzed for VF-14 and NEIVFQ-25. According to partial plots and scatter plots of studentized residuals with unstandardized predicted values, a linear relationship exists between independent variables and dependent variables. Durbin-Watson values are 1.567, 1.254 for VF-14, and NEI-VFQ25 , respectively, which means that observations are independent of each other. It is validated that the data is equivariant through a scatter plot between the studentized residuals and the unstandardized predicted values. There is no multicollinearity since tolerance is over 0.1. Through the outlier test, a total of five VF-14 outliers, and six NEI-VFQ-25 outliers were deleted (outlier standard: studentized deleted residuals $>3$ times of standard deviation for observations, leverage values $>0.2$ or Cook's distance values $>1$ ). The regression models are statistically significant, with adjusted $R^{2}=0.226$ and 0.353 for VF-14 and NEIVFQ-25, respectively. The level of significance is $P<0.05$.

\section{Results}

A total of 831 eyes from 831 patients were enrolled, and there were 137 subjects dropped out for incomplete clinical data or abnormal values. Overall, there were 694 subjects included with a drop-out rate of $16.5 \%$. The demographic and clinical characteristics of subjects are presented in Table 1. UDVAs of the operative eyes range from 0 to 2.0 (LogMAR), and vision impairment is shown in Fig. 1a. Mean LOCS III scores were $2.76 \pm 0.78, \quad 2.45 \pm 0.97, \quad$ and $2.11 \pm 1.13$ for NO, C, and $P$, respectively. Figure $1 \mathrm{~b}$ shows the distribution of various LOCS III scores. There were 333 eyes (48.0\%) in Group C1 and 361 eyes $(52.0 \%)$ in Group C2. The VF-14 score and the total or subscale scores of NEI-VFQ-25 are presented in Table 1.

Spearman correlation test was applied among age, LOCS III NO, C, P scores, UDVA, and each scale score (Table 2). LOCS III C, P scores are negatively correlated with the VF-14 score, total and most subscale scores of NEI-VFQ-25, whereas LOCS III NO score is positively correlated with the VF-14 score, total and most subscale scores of NEI-VFQ-25. UDVA of either eye is negatively correlated with the VF-14 score and the total score of NEI-VFQ-25 (Table 2). A line graph was plotted to illustrate the association among LOCS III scores, UDVA, the VF14 score, and the total score of NEI-VFQ-25 (Fig. 2). With the increase in the LOCS III NO score, UDVA decreases, while the VF-14 score and the total score of NEI-VFQ-25 tend to increase. With the increase in the LOCS III C score, UDVA, the VF-14 score, and the total score of NEI-VFQ-25 decrease. For the LOCS III $\mathrm{P}$ score, a U-shaped tendency is presented, and " 3 " seems to be a turning point.

Mann-Whitney $U$ test shows that male has a higher total score of NEI-VFQ-25 compared with female $(78.93 \pm 17.94$ versus $74.36 \pm 19.25, \quad P<0.01)$; patients with hypertension have a higher total score of NEI-VFQ-25 $\quad(80.98 \pm 15.82 \quad$ versus $72.74 \pm 20.09, P<0.01)$ and a higher VF-14 score $(48.58 \pm 13.71$ versus $45.32 \pm 15.76, \quad P<0.01)$; patients with diabetes have a higher total score of NEI-VFQ-25 (80.49 \pm 15.73 versus $74.86 \pm 19.54$, $P<0.01)$. Patients in Group C1 have a higher VF-14 score, higher total and subscale scores of NEI-VFQ-25 than in Group C2 (Supplementary Table, Fig. 3). 
Table 1 Demographic and clinical characteristics of subjects, VF-14 scores and NEF-VFQ-25 scores $(n=694)$

\begin{tabular}{|c|c|c|}
\hline Variables & Mean (SD) & Median \\
\hline Age (year) & $70.23(9.93)$ & 71.00 \\
\hline \multicolumn{3}{|l|}{ UDVA (LogMAR) } \\
\hline Op-eye & $0.76(0.39)$ & 0.70 \\
\hline Non-op-eye & $0.46(0.35)$ & 0.40 \\
\hline LOCS III NO score & $2.76(0.78)$ & 3.00 \\
\hline LOCS III C score & $2.45(0.97)$ & 3.00 \\
\hline LOCS III P score & $2.11(1.13)$ & 2.00 \\
\hline VF-14 & $46.67(15.02)$ & 45.83 \\
\hline \multicolumn{3}{|l|}{$N E F-V F Q-25$} \\
\hline General health & 39.66 (19.79) & 50.00 \\
\hline General vision & $46.31(16.95)$ & 40.00 \\
\hline Ocular pain & $84.78(20.86)$ & 100.00 \\
\hline Near activities & $68.36(24.66)$ & 75.00 \\
\hline Distance activities & $77.61(23.62)$ & 83.33 \\
\hline Social functioning & $86.62(22.31)$ & 100.00 \\
\hline Mental health & $78.87(24.82)$ & 93.75 \\
\hline Role difficulties & $71.52(29.31)$ & 75.00 \\
\hline Dependency & $81.15(26.98)$ & 100.00 \\
\hline Driving $(n=224)$ & $73.23(35.08)$ & 91.67 \\
\hline Color vision & $86.78(25.11)$ & 100.00 \\
\hline Peripheral vision & $79.57(25.62)$ & 100.00 \\
\hline Total score & $76.16(18.87)$ & 82.21 \\
\hline \multicolumn{3}{|l|}{ Number $(\%)$} \\
\hline Gender (male/female) & \multicolumn{2}{|c|}{$273(39.3) / 421(60.7)$} \\
\hline Hypertension (no/yes) & \multicolumn{2}{|c|}{$406(58.5) / 288(41.5)$} \\
\hline Diabetes (no/yes) & \multicolumn{2}{|c|}{$534(76.9) / 160(23.1)$} \\
\hline
\end{tabular}

$S D$ standard deviation, UDVA uncorrected distance visual acuity, Op-eye operative eye, $N O$ nuclear opalescence, $C$ cortical, $P$ posterior subcapsular, LOCS III Lens Opacities Classification System III, VF-14 Visual Function Index-14, NEI-VFQ-25 25-item National Eye Institute Visual Functioning Questionnaire

Multiple linear regression analysis for VF-14 and NEI-VFQ-25 is presented in Table 3.

\section{Discussion}

The mean of UDVA (LogMAR) of op-eye in our study is 0.76 , which is better than severe vision impairment or blindness. Among these patients undergoing cataract surgery, only $28.8 \%$ of them had severe vision impairment or blindness. Most of them are patients with moderate vision impairment. We also noticed that even patients with no apparent vision impairment were going to receive surgery. Patients with cataract used to receive surgery when they had to, but now they determine to receive surgery when their vision cannot meet their needs in life, such as the demand for driving. These phenomena indicate that cataract surgery is gradually transforming from an "unblinding surgery" to a "refractive surgery" for better vision-specific quality of life.

Some studies found a stronger association between subjective and objective visual function among the better eyes, rather than the worse eyes or operative eyes [8, 9, 19, 24]. Our data showed a significant association between UDVA of the op-eye or non-opeye and self-assessing questionnaires, even after adjusting confounding factors. In the multiple regression model, UDVA of op-eye has a more remarkable effect on the VF-14 score, while UDVA of non-op-eye has a more prominent effect on the total score of NEIVFQ-25. Such paradox potentially revealed that these two questionnaires reflect the vision function of different eyes. Besides, we analyzed the association of the VF-14 score and the total score of NEI-VFQ-25, in which they were moderately correlated with each other. Therefore, we probably chose VF-14 to evaluate the influence of the op-eye on subjective vision function. Otherwise, NEI-VFQ-25 would be a better choice for the non-op-eye. The correlation between UDVA and scores of self-assessing questionnaires is not that strong, which is consistent with previous studies [8, 14, 25]. Therefore, such self-assessing questionnaires like VF-14 or NEI-VFQ-25 are much necessary to assist ophthalmologists in evaluating the patients with cataract. However, either VF-14 or NEIVFQ-25 is too complicated for some patients to understand and for doctors to operate or calculate, and this complexity makes these questionnaires hard for a widespread use. Therefore, it is urgently needed to develop a much simpler scale to screen or evaluate patients.

Chew et al. [26] showed that all types of cataract negatively affected the VF-14 score. Except for nuclear cataract, the results of cortical cataract and posterior subcapsular cataract in another study were similar [10]. These phenomena are consistent with our findings. In the multiple regression model, LOCS III NO score and $\mathrm{C}$ score are significantly associated with 
Fig. 1 Bar graph showing the distribution of vision impairment, LOCS III NO, $\mathrm{C}$, and $\mathrm{P}$ scores among patients with age-related cataract. a The distribution of vision impairment. b The distribution of LOCS III $\mathrm{NO}, \mathrm{C}$, and $\mathrm{P}$ scores. LOCS Lens Opacities

Classification System, $\mathrm{NO}$ nuclear opalescence, $C$ cortical, $P$ posterior subcapsular
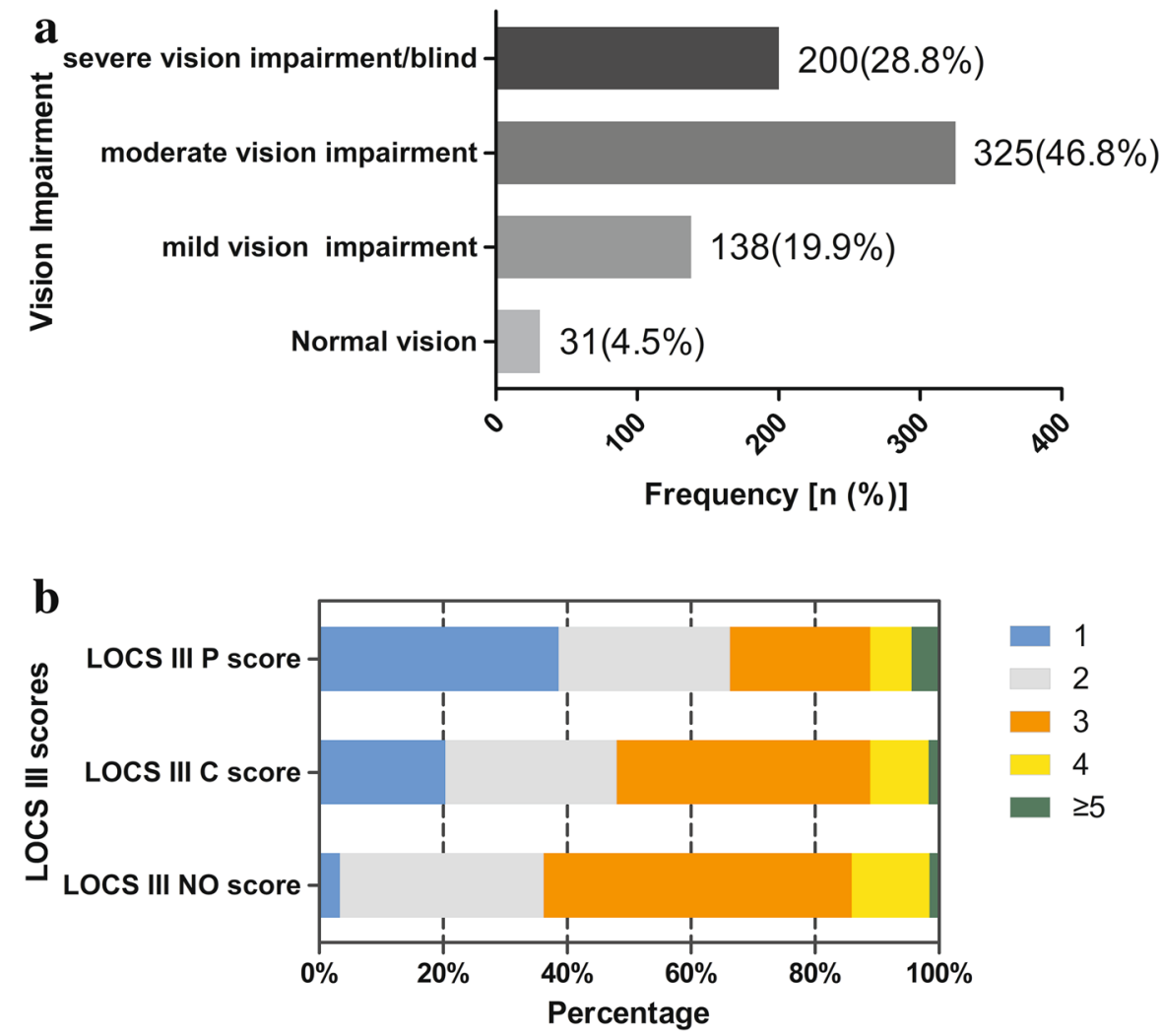

Table 2 Correlation between characteristics and self-reported questionnaire scores $(n=694)$

\begin{tabular}{|c|c|c|c|c|c|c|}
\hline \multirow[t]{2}{*}{ Scale scores } & \multirow[t]{2}{*}{ Age (year) } & \multicolumn{3}{|c|}{ LOCS III scores } & \multicolumn{2}{|c|}{ UDVA (LogMAR) } \\
\hline & & NO & $\mathrm{C}$ & $P$ & Op-eye & Non-op-eye \\
\hline VF-14 & -0.069 & $0.087 *$ & $-0.188^{* *}$ & $-0.146^{* *}$ & $-0.344 * *$ & $-0.317 * *$ \\
\hline General health & $-0.188 * *$ & 0.019 & -0.066 & 0.013 & $-0.099 * *$ & $-0.230 * *$ \\
\hline General vision & $-0.094 *$ & $-0.126^{* *}$ & -0.050 & -0.029 & $-0.221 * *$ & $-0.328 * *$ \\
\hline Ocular pain & 0.071 & $0.169 * *$ & $-0.184 * *$ & $-0.144 * *$ & $-0.212 * *$ & $-0.239 * *$ \\
\hline Near activities & $-0.120 * *$ & 0.043 & $-0.152 * *$ & $-0.117 * *$ & $-0.275^{* *}$ & $-0.379 * *$ \\
\hline Distance activities & $-0.083^{*}$ & $0.117 * *$ & $-0.197 * *$ & $-0.150 * *$ & $-0.369 * *$ & $-0.494 * *$ \\
\hline Social functioning & -0.021 & $0.138 * *$ & $-0.218 * *$ & $-0.183 * *$ & $-0.322 * *$ & $-0.347 * *$ \\
\hline Mental health & -0.037 & $0.140 * *$ & $-0.194 * *$ & $-0.143 * *$ & $-0.329 * *$ & $-0.373 * *$ \\
\hline Role difficulties & -0.019 & $0.082 *$ & $-0.224 * *$ & $-0.094 *$ & $-0.300 * *$ & $-0.399 * *$ \\
\hline Dependency & -0.033 & $0.141 * *$ & $-0.177^{* *}$ & $-0.161 * *$ & $-0.316^{* *}$ & $-0.369 * *$ \\
\hline Driving & -0.012 & 0.020 & $-0.265^{* *}$ & 0.007 & $-0.229 * *$ & $-0.333 * *$ \\
\hline Color vision & -0.012 & $0.133 * *$ & $-0.208 * *$ & $-0.171 * *$ & $-0.296 * *$ & $-0.301 * *$ \\
\hline Peripheral vision & -0.044 & $0.134 * *$ & $-0.184 * *$ & $-0.182 * *$ & $-0.342 * *$ & $-0.401 * *$ \\
\hline Total score of NEI-VFQ-25 & -0.050 & $0.097 *$ & $-0.223^{* *}$ & $-0.160 * *$ & $-0.376 * *$ & $-0.497 * *$ \\
\hline
\end{tabular}

$* P<0.05 ; * * P<0.01$

UDVA uncorrected distance visual acuity, Op-eye operative eye, $N O$ nuclear opalescence, $C$ cortical, $P$ posterior subcapsular, $L O C S$ III Lens Opacities Classification System III, VF-14 Visual Function Index-14, NEI-VFQ-25 25-item National Eye Institute Visual Functioning Questionnaire 

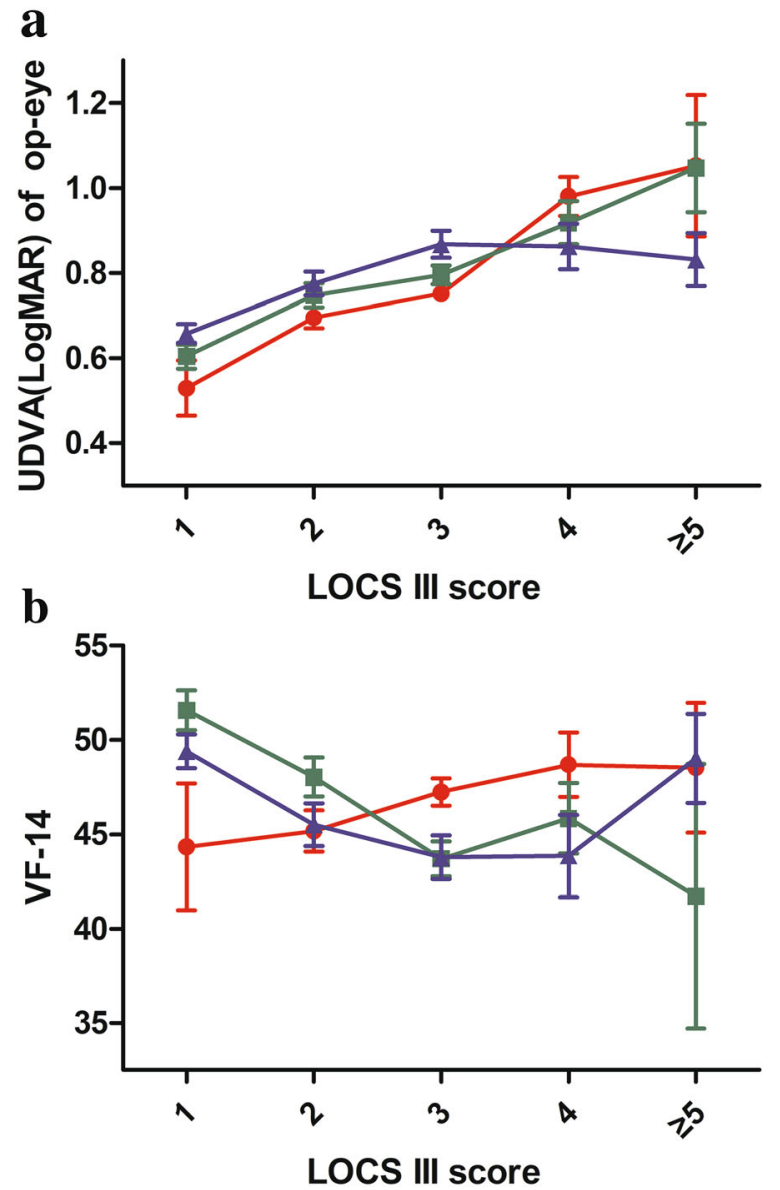

Fig. 2 Line graph showing the correlation among UDVA, the VF-14 score, the total score of NEI-VFQ-25, and LOCS III scores. a UDVA of the op-eye changing with LOCS III scores. b The VF-14 score changing with LOCS III scores. c The total score of NEI-VFQ-25 changing with LOCS III score. UDVA

subjective visual function except for the LOCS III P score. We notice that, when LOCS III NO score $<4$, patients with higher LOCS III NO scores tend to have a better subjective visual function, which is against the previous studies $[9,26]$. It may not be surprising since a myopic shift caused by nuclear cataract [27] partially corrects the presbyopia, which probably helps improve the subjective visual function. Therefore, for nuclear cataract, it is probably not necessary to receive surgery that radically. Cortical cataract is negatively associated with subjective visual function. To find a cutoff for the LOCS III C score associated with visual function, we divided the data into two groups, Group C1 (LOCS III C score $\leq 2$ ) and Group $\mathrm{C} 2$ (LOCS III C score $>2$ ). We found that patients in

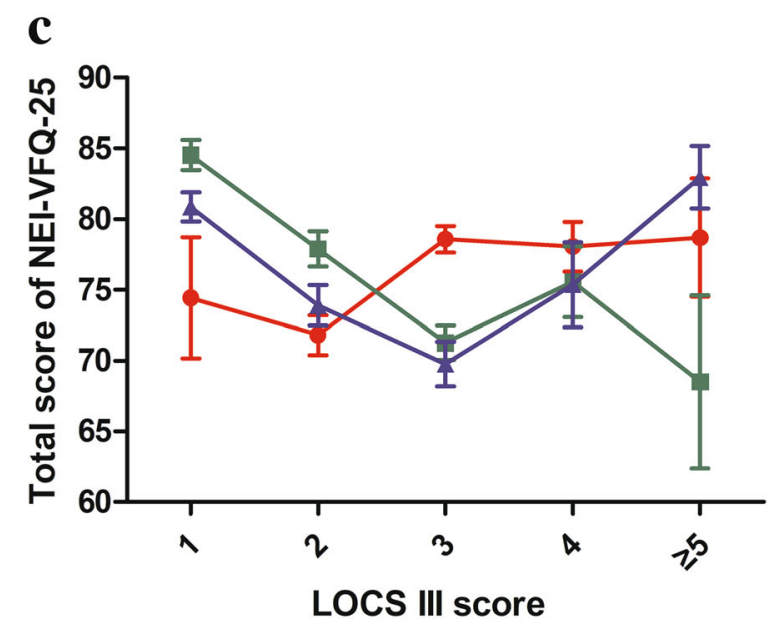

uncorrected distance visual acuity, op-eye operative eye, $V F-14$ the Visual Function Index-14, NEI-VFQ-25 the 25-item National Eye Institute Visual Functioning Questionnaire, LOCS Lens Opacities Classification System, $N O$ nuclear opalescence, $C$ cortical, $P$ posterior subcapsular. Error bars indicate SEM

Group C2 had a significantly worse subjective and objective visual function. As we mentioned above, it is hard to apply such questionnaires widely. This cutoff could reflect the situation of patients' subjective visual function. Therefore, we recommend patients with higher LOCS III C score or severe cortical change of lens to receive surgery more actively, and "LOCS III C score $>2$ " should be a potential cutoff as a reference for cataract surgery.

In conclusion, our study suggests that patients with age-related cataract are willing to receive cataract surgery as their visions are not able to satisfy their needs in life at present, even their visual acuities are acceptable. This phenomenon may drive the transformation of the existing medical model of cataract 
Fig. 3 Bar graph showing the difference of UDVA, the VF-14 score, the total and subscale scores of NEIVFQ-25 score between Group C1 (LOCS III C score $\leq 2)$ and Group C2 (LOCS III C score $>2$ ). $U D V A$ uncorrected distance visual acuity; $V F-14$ the Visual Function Index-14; $N E I$-VFQ-25 the 25-item

National Eye Institute

Visual Functioning

Questionnaire.

$* * * P<0.001$ analysis of variance. Error bars indicate SD
LOCS III C score

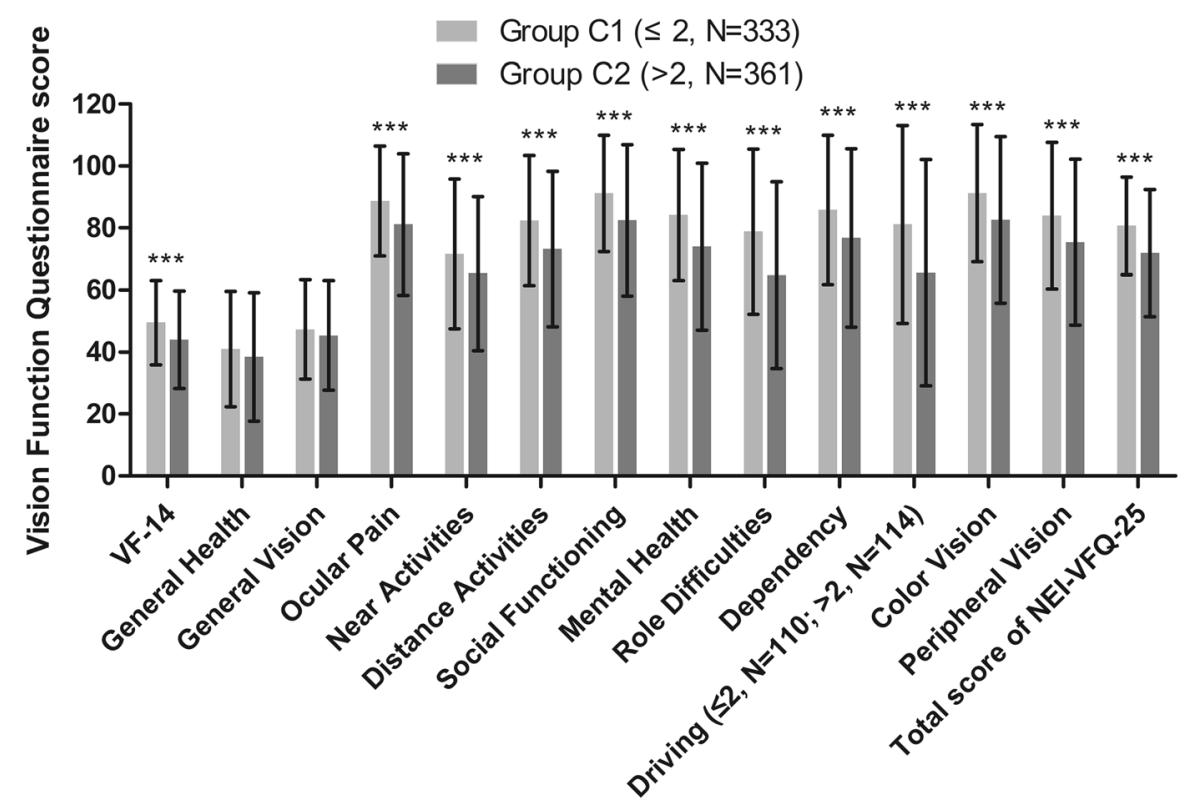

Table 3 Multiple linear regression model for VF-14, total score of NEI-VFQ-25

\begin{tabular}{|c|c|c|c|c|c|c|}
\hline & \multicolumn{3}{|l|}{ VF-14 } & \multicolumn{3}{|c|}{ Total score of NEI-VFQ-25 } \\
\hline & $\beta$ & SE & $\mathrm{SC}$ & $\beta$ & SE & $\mathrm{SC}$ \\
\hline (Constant) & 66.056 & 4.255 & - & 96.829 & 4.828 & - \\
\hline Age & -0.177 & 0.053 & $-0.120 * *$ & -0.094 & 0.061 & -0.052 \\
\hline Gender & -1.432 & 1.013 & -0.048 & -4.027 & 1.151 & $-0.108 * *$ \\
\hline UDVA of op-eye & -11.261 & 1.474 & $-0.294 * *$ & -13.176 & 1.662 & $-0.280 * *$ \\
\hline UDVA of non-op-eye & -9.731 & 1.508 & $-0.232 * *$ & -17.955 & 1.712 & $-0.345^{* *}$ \\
\hline LOCS III NO score & 3.826 & 0.712 & $0.203 * *$ & 4.618 & 0.809 & $0.198 * *$ \\
\hline LOCS III C score & -0.878 & 0.533 & -0.058 & -1.286 & 0.604 & $-0.069^{*}$ \\
\hline LOCS III P score & -0.399 & 0.448 & -0.031 & -0.558 & 0.510 & -0.035 \\
\hline Hypertension & 1.369 & 1.056 & 0.046 & 4.999 & 1.195 & $0.136^{* *}$ \\
\hline Diabetes & 0.706 & 1.214 & 0.020 & 3.048 & 1.378 & $0.071 *$ \\
\hline
\end{tabular}

$* P<0.05 ; * * P<0.01$

$S E$ standardized error, $S C$ standardized coefficients, $U D V A$ uncorrected distance visual acuity, $O p$-eye operative eye, $N O$ nuclear opalescence, $C$ cortical, $P$ posterior subcapsular, LOCS III Lens Opacities Classification System III, VF-14 Visual Function Index-14, NEI-VFQ-25 25-item National Eye Institute Visual Functioning Questionnaire

surgery, from an "unblinding surgery" to a "refractive surgery" for better vision-specific quality of life. Nuclear, cortical, and posterior subcapsular cataracts can affect the subjective and objective visual function, respectively. Cortical cataract is negatively associated with subjective visual function, while nuclear cataract has an inverse trend. "LOCS III C score $>2$ " is probably a potential cutoff as a reference for cataract surgery without self-assessing questionnaires. 
Funding This work was supported by Capital's Funds for Health Improvement and Research (2018-2-4093).

\section{Compliance with ethical standards}

Conflict of interest The authors declare that they have no conflict of interest.

Ethical approval All procedures performed in studies involving human participants were in accordance with the ethical standards of the institutional and national research committee (Peking University Third Hospital Medical Science Research Ethics Committee, M2018093) and with the 1964 Helsinki Declaration and its later amendments or comparable ethical standards.

Informed consent Informed consent was obtained from all individual participants included in the study.

Open Access This article is licensed under a Creative Commons Attribution 4.0 International License, which permits use, sharing, adaptation, distribution and reproduction in any medium or format, as long as you give appropriate credit to the original author(s) and the source, provide a link to the Creative Commons licence, and indicate if changes were made. The images or other third party material in this article are included in the article's Creative Commons licence, unless indicated otherwise in a credit line to the material. If material is not included in the article's Creative Commons licence and your intended use is not permitted by statutory regulation or exceeds the permitted use, you will need to obtain permission directly from the copyright holder. To view a copy of this licence, visit http://creativecommons.org/licenses/by/4.0/.

\section{References}

1. Pascolini D, Mariotti SP (2012) Global estimates of visual impairment: 2010. Br J Ophthalmol 96:614-618

2. Polack S, Eusebio C, Fletcher A, Foster A, Kuper H (2010) Visual impairment from cataract and health related quality of life: results from a case-control study in the Philippines. Ophthalmic Epidemiol 17:152-159

3. Chandrasekaran S, Wang JJ, Rochtchina E, Mitchell P (2008) Change in health-related quality of life after cataract surgery in a population-based sample. Eye (Lond) 22:479-484

4. Helbostad JL, Oedegaard M, Lamb SE, Delbaere K, Lord SR, Sletvold O (2013) Change in vision, visual disability, and health after cataract surgery. Optom Vis Sci 90:392-399

5. Owsley C, McGwin GJ, Scilley K, Meek GC, Seker D, Dyer A (2007) Impact of cataract surgery on health-related quality of life in nursing home residents. $\mathrm{Br} \mathrm{J}$ Ophthalmol 91:1359-1363

6. Ni W, Li X, Hou Z, Zhang H, Qiu W, Wang W (2015) Impact of cataract surgery on vision-related life performances: the usefulness of real-life vision test for cataract surgery outcomes evaluation. Eye (Lond) 29:1545-1554
7. Lamoureux EL, Fenwick E, Pesudovs K, Tan D (2011) The impact of cataract surgery on quality of life. Curr Opin Ophthalmol 22:19-27

8. Ni W, Li X, Ao M, Zhang H, Hou Z, Si S et al (2012) Using the real-life vision test to assess the functional vision of agerelated cataract patients. Eye (Lond) 26:1402-1411

9. Pan AP, Wang QM, Huang F, Huang JH, Bao FJ, Yu AY (2015) Correlation among lens opacities classification system III grading, visual function index-14, pentacam nucleus staging, and objective scatter index for cataract assessment. Am J Ophthalmol 159(241-7):e2

10. Cochener B, Patel SR, Galliot F (2016) Correlational analysis of objective and subjective measures of cataract quantification. J Refract Surg 32:104-109

11. Chylack LJ, Wolfe JK, Singer DM, Leske MC, Bullimore MA, Bailey IL et al (1993) The Lens Opacities Classification System III. The longitudinal study of cataract study group. Arch Ophthalmol 111:831-836

12. Makhotkina NY, Berendschot T, van den Biggelaar F, Weik A, Nuijts R (2018) Comparability of subjective and objective measurements of nuclear density in cataract patients. Acta Ophthalmol 96:356-363

13. Toprak AB, Eser E, Guler C, Baser FE, Mayali H (2005) Cross-validation of the Turkish version of the 25-item National Eye Institute Visual Functioning Questionnaire (NEI-VFQ 25). Ophthalmic Epidemiol 12:259-269

14. Lin JC, Chie WC (2010) Psychometric validation of the Taiwan Chinese version of the 25-item National Eye Institute Visual Functioning Questionnaire. J Eval Clin Pract 16:619-626

15. Mangione CM, Lee PP, Gutierrez PR, Spritzer K, Berry S, Hays RD (2001) Development of the 25-item National Eye Institute Visual Function Questionnaire. Arch Ophthalmol 119:1050-1058

16. Perea-Milla E, Vidal S, Briones E, Aguirre U, Bare M, Fernandez DLN et al (2011) Development and validation of clinical scores for visual outcomes after cataract surgery. Ophthalmology 118:9-16

17. Quintana JM, Escobar A, Bilbao A, Blasco JA, Lacalle JR, Bare M et al (2009) Validity of newly developed appropriateness criteria for cataract surgery. Ophthalmology 116(409-417):e3

18. Gresset J, Boisjoly H, Nguyen TQ, Boutin J, Charest M (1997) Validation of French-language versions of the Visual Functioning Index (VF-14) and the Cataract Symptom Score. Can J Ophthalmol 32:31-37

19. Alonso J, Espallargues M, Andersen TF, Cassard SD, Dunn E, Bernth-Petersen P et al (1997) International applicability of the VF-14. An index of visual function in patients with cataracts. Ophthalmology 104:799-807

20. Lundstrom M, Pesudovs K (2011) Questionnaires for measuring cataract surgery outcomes. J Cataract Refract Surg 37:945-959

21. Szakats I, Sebestyen M, Toth E, Purebl G (2017) Dry eye symptoms, patient-reported visual functioning, and health anxiety influencing patient satisfaction after cataract surgery. Curr Eye Res 42:832-836

22. Gali HE, Sella R, Afshari NA (2019) Cataract grading systems: a review of past and present. Curr Opin Ophthalmol 30:13-18 
23. Nickels S, Schuster AK, Singer S, Wild PS, Laubert-Reh D, Schulz A et al (2017) The National Eye Institute 25-item Visual Function Questionnaire (NEI VFQ-25)—reference data from the German population-based Gutenberg Health Study (GHS). Health Qual Life Outcomes 15:156

24. Steinberg EP, Tielsch JM, Schein OD, Javitt JC, Sharkey P, Cassard SD et al (1994) The VF-14. An index of functional impairment in patients with cataract. Arch Ophthalmol 112:630-638

25. Las HC, Quintana JM, Bilbao A, Garcia S, Lafuente I (2011) Visual acuity level, ocular morbidity, and the better seeing eye affect sensitivity and responsiveness of the visual function index. Ophthalmology 118:1303-1309
26. Chew M, Chiang PP, Zheng Y, Lavanya R, Wu R, Saw SM et al (2012) The impact of cataract, cataract types, and cataract grades on vision-specific functioning using Rasch analysis. Am J Ophthalmol 154(29-38):e2

27. Diez AM, Garcia DM, Peris MC (2015) Refractive changes in nuclear, cortical and posterior subcapsular cataracts, effect of the type and grade. J Optom. 8:86-92

Publisher's Note Springer Nature remains neutral with regard to jurisdictional claims in published maps and institutional affiliations. 